J. Lake Sci. (湖泊科学) , 2015, 27(1): 175-182

http://www. jlakes. org. E-mail : jlakes@niglas.ac.cn

(C) 2015 by Journal of Lake Sciences

\title{
滇池流域水生态功能一二级分区研究”
}

\author{
高喆 ${ }^{1}$, 曹晓峰 ${ }^{1,2 * *}$, 黄 艺 ${ }^{1}$, 李发荣 ${ }^{3}$ \\ (1: 北京大学环境科学与工程学院,北京 100871) \\ (2: 北京大学环境与能源学院, 深圳 518055 ) \\ (3: 昆明市环境监测中心, 昆明 650228)
}

摘 要: 水生态功能分区是流域水资源管理、水环境保护、水生态恢复的基础,尤其是与人类活动紧密相连而又矛盾重重 的湖泊流域,其水生态功能分区是实现流域可持续发展的必要条件, 而如何科学合理地对湖泊流域进行水生态功能分 区,成为流域综合管理过程中亟需解决的问题. 以滇池流域为例, 立足于滇池流域水生态系统存在的问题, 确定了流域 一、二级水生态功能区的主导功能; 以水文完整性为基础, 分别针对一、二级分区划分子流域单元; 以生态功能区划的生 态系统服务功能、尺度效应、地域分异规律等相关理论为基础, 识别影响滇池流域水生态功能的关键因子,构建滇池流域 一、二级水生态功能区的指标体系; 对多指标进行空间叠加聚类, 并根据滇池流域的水量水质特征对分区边界进行微调, 将滇池流域划分为 5 个一级区和 10 个二级区; 同时采用着生藻、水丝蚫的生物密度对分区结果进行合理性评价; 在此基 础上,对水生态功能分区存在的问题进行探讨.

关键词: 水生态功能分区;滇池流域;指标体系;合理性评价

\section{Research of level | and || aquatic ecological function regionalization in Lake Dianchi basin}

\author{
GAO Zhe ${ }^{1}$, CAO Xiaofeng ${ }^{1,2}$, HUANG $\mathrm{Yi}^{1}$ \& LI Farong ${ }^{3}$ \\ (1: College of Environmental Sciences and Engineering, Peking University, Beijing 100871, P. R. China) \\ (2: School of Environment and Energy, Peking University, Shenzhen 518055, P. R. China) \\ (3:Kunming Environmental Monitoring Center, Kunming 650228, P. R. China)
}

\begin{abstract}
The aquatic ecological function regionalization is the basic requirement of water resources management, water environment protection and water ecology restoration. Especially for lake basins which are connected closely with human activities and filled with inconsistencies, the aquatic ecological function regionalization is an indispensable condition of realizing sustainable development in the watershed. So how to delineate reasonable ecological function regionalization becomes the major issue to be addressed in the integrated watershed management. In the case of Lake Dianchi basin, the dominant water ecological functions are first determined according to the current problems of water ecosystems. And in the premise of hydrological integrity, sub-catchment units are divided for the first and the second level regionalization respectively. Then we indentify the key factors that affect water ecological function significantly and construct the index system for the watershed based on the relative theories, including ecosystem service function, scale effect and rule of territorial differentiation. The overlaying and clustering methods are used for multiple indices. Then final boundary is adjusted slightly according to water quantity and quality distribution. The consequence shows that Lake Dianchi basin is divided into 5 level I ecological function regions and 10 level II ecological function regions. By using the density of periphytic algae and Limnodrilus, assessment is made on the reasonability of regionalization. Finally the problems remained in the water ecological function regionalization are discussed.
\end{abstract}

Keywords: Water ecological function regionalization; Lake Dianchi basin; index system; reasonability evaluation

流域水生态功能区划是以恢复流域持续性、完整性生态系统健康为目标,针对流域内自然地理环境分

* 国家水体污染控制与治理科技重大专项项目 (2012ZX07501002-006) 资助. 2014-01-19 收稿;2014-04-15 收修 改稿. 高喆(1990 ),女,硕士研究生;E-mail:gigi@ pku. edu. cn.

** 通信作者;E-mail:caoxf1273@163.com. 
异性、生态系统多样性以及经济与社会发展不均衡性的现状,结合水资源保护与可持续开发利用、流域综合 管理与流域生态系统管理的思想, 整合与分异流域生态系统服务功能对流域水陆耦合体影响的生态敏感 性, 进而在流域尺度上进行的水生态功能区的划分. 其明确了水生态功能区的主导生态系统服务功能以及 生态环境保护的目标,划定了对流域生态系统健康起关键作用的重要生态功能区域 ${ }^{[1]}$.

从 1980s 开始, 国际上从生态系统健康角度出发, 基于水生态系统的环境管理日益成为主流. 这种基于 生态系统的环境管理的基本单元就是水生态分区. USEPA 于 1987 年首次提出了美国水生态分区方案 ${ }^{[2]}$. 在 随后的几十年内, 英国 ${ }^{[3]}$ 、澳大利亚 ${ }^{[4]}$ 、欧盟 ${ }^{[5]}$ 等纷纷开展针对本国国情的水生态分区. 我国对水生态分区 的研究起步较晚, 孟伟等 ${ }^{[6]}$ 于 2006 年对辽河流域水生态分区进行了探索, 提出了基于水生态区的环境管理 技术支撑体系. 孙小银等 ${ }^{[7-8]}$ 在 2009 年通过对比中美生态分区的异同, 对我国水生态分区的范围、分类指标 以及与现有分区的协调进行了探讨.

水生态功能分区是在水生态分区的基础上, 考虑生态系统和生态过程的完整性以及人类活动对水生态 系统产生的影响, 以实现 “分类、分区、分级和分期” 的多维流域综合管理模式为终极目的的基础单元. 一方 面, 水生态功能分区可以作为流域水量、水质管理的基本空间单元, 有利于进行更精细化的水资源配置以及 确定流域水环境基准 ${ }^{[9]}$; 另一方面, 水生态功能分区是开展水生态系统健康评估、识别水生态功能和确定水 生态保护目标的基本单元 ${ }^{[10-11]}$, 是保护珍稀生物、恢复流域健康的基础. 目前, 在海河 ${ }^{[12]}$ 、辽河 ${ }^{[13-15]}$ 、太子 河 ${ }^{[16]}$ 等河流流域进行了水生态功能区划的研究, 但是针对湖泊流域进行的水生态功能区划研究较少, 仅有 太湖 ${ }^{[17-18]} 、$ 巢湖 ${ }^{[19]} 、$ 、洱海 ${ }^{[20]}$ 流域. 与河流流域相比, 湖泊流域湖泊与人湖、出湖河流并存. 而以滇池为代表的 高原湖泊, 其放射状的水系结构更为复杂, 支流水系更多, 而出流水系普遍较少, 故湖泊更新周期长, 生态系 统更为脆弱 ${ }^{[21]}$. 考虑到湖泊流域的开放性和复杂性, 基于其固有的生态特性, 大尺度的分区应将湖泊作为整 个流域的“汇”, 这也是湖泊流域和河流流域的区划差异. 湖泊作为流域的“汇”, 受纳了地表径流携带的流 域陆地生态系统的物质、能量和信息, 具体表现为水流和水量变化、营养物质输人输出、生物群落动态和演 替、湖 (河) 岸土地利用变化等物理、化学和生物过程, 以及人类活动对这些过程的影响. 通过这些过程及其 人类活动的影响, 形成了流域地球化学功能、水文水动力功能和生物生态功能及其供给服务、调节服务、文 化服务和支持服务. 根据源一汇理论 ${ }^{[22]}$, 湖泊是整个流域水生态服务功能的主导体现. 因此, 结合高原湖泊 的特征, 对其水生态功能区划进行深人研究显得尤为重要.

滇池流域地处云贵高原,紧临云南省会昆明, 是我国重点湖泊流域之一, 其集供水、水源涵养、维持生物 多样性、净化环境等生态服务功能于一体. 但由于自然环境变化和人类活动的双重影响, 流域水生态系统健 康遭到严重破坏, 导致水环境质量下降、水生生物栖息地锐减、生物多样性减少等水生态功能退化现象的出 现, 其中富营养化问题尤为突出. 在滇池流域实行流域综合管理, 对陆地和水体作统一规划和管理, 或许是 解决上述问题的有效途径 ${ }^{[23-25]}$. 而水生态功能分区作为流域综合管理的基础单元, 是实现水质管理转向流 域管理的必要条件. 因此,该论文将以生态功能区划的生态系统服务功能、尺度效应、地域分异规律等相关 理论为基础 ${ }^{[26]}$, 针对滇池流域水量不足和水质较差的问题, 构建一套适用于滇池流域的水生态功能区划方 法, 并重点对高原湖泊流域的水生态功能区划方法、指标选取、合理性评价进行讨论, 以期为滇池的综合流 域管理提供技术基础, 为其他高原湖泊流域的水生态功能区划提供示范.

\section{1 数据和方法}

\section{1 滇池流域概况}

滇池流域 $\left(24^{\circ} 29^{\prime} \sim 25^{\circ} 28^{\prime} \mathrm{N}, 102^{\circ} 29^{\prime} \sim 103^{\circ} 01^{\prime} \mathrm{E}\right.$ ) 水面面积 $2920 \mathrm{~km}^{2}$, 为南北长、东西窄的湖盆地, 位于 云贵高原中部, 地处长江、红河、珠江 3 大水系分水岭地带. 西有横断山脉, 东临滇东高原, 北临乌蒙山、梁王 山, 地势由北向南逐渐降低. 滇池属于长江流域金沙江水系, 为断陷构造湖泊, 湖面面积约为 $300 \mathrm{~km}^{2}$, 是云 贵高原湖面最大的淡水湖泊. 人滇池水系有 12 个, 主要人湖河流 29 条, 呈向心状流入滇池. 滇池自 1996 年 修建了船闸以后就被分割为既相互联系,但又几乎互不交换的草海、外海两部分.

\section{2 分区目的与原则}

滇池流域作为一个水生态系统, 具有提供、支持、调节与文化多重水生态服务功能. 近年来, 水资源总量 
不足和水质整体较差是滇池流域水生态系统所面临的主要问题, 自然过程和人类活动不同程度地降低了流 域水生态系统的水资源支持功能和水质调节功能 ${ }^{[27]}$, 因此明确一级分区的主导功能是水资源支持功能,二 级分区的主导功能是水质调节功能. 而分区的目的即为体现每级分区主导功能的空间差异性.

滇池流域水生态功能分区遵循的原则如下. 自然和人工影响兼顾原则: 以流域完整性为主, 同时考虑水 利工程的截断作用; 源一汇分开原则: 分水线的封闭性决定了湖泊作为流域下游的汇,一级分区首先将陆地 集水区 (源) 和湖体 (汇) 分开,将湖体作为一单独分区; 共轭性和一致性原则: 合并子流域单元时保证同一 分区中具有统一的水生态功能; 水陆耦合原则 : 以对水生态功能具有直接影响的陆地驱动因子来分区, 以水 生物状况指标来校验一级分区结果,二级分区在一级分区基础上进行,不可打破一级分区的边界.

\section{3 分区基本单元}

子流域单元的划分是水生态功能区划的首要工作. 在划分一级子流域单元时,充分体现水资源支持功 能的空间差异性, 故依据对主导功能影响的地形特征和水系分布特征, 基于 DEM 和水系的连通性, 在 ArcGIS 中的 Hydrology 模块中进行提取.二级子流域单元划分时, 基于一级子流域单元划分结果, 考虑子流域单 元内人为活动对水文过程的截断影响,将一级子流域单元进行再划分.

\section{4 分区指标}

水生态功能分区实质上是分区尺度由大到小的等级嵌套的分区体系, 指标的选择通常与尺度效应有

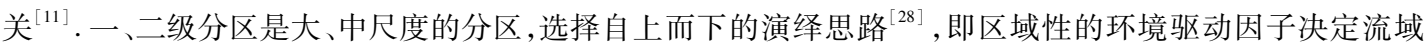
的景观结构特征, 从而决定水生态系统的生物群落结构 ${ }^{[29]}$. 同时, 充分考虑水陆耦合以及自然和人类活动的 共同作用选择指标 ${ }^{[30-31]}$. 一级分区主要反映水文过程和气候条件对水生态系统的影响,应具有相似的地貌、 气象和水文特征 ${ }^{[32]}$, 因此选取多年年均降水量、多年年均干燥度、高程、坡度、土壤类型、植被覆盖指数 $(N D-$ $V I) 、$ 河网密度、湖库率作为一级分区的备选指标.二级分区应该反映水生态系统的空间差异以及土壤、植被 和人类活动等对水生态系统功能的影响 ${ }^{[32]}$, 土地利用方式和社会经济对其水质调节功能的空间差异影响显 著 ${ }^{[33]}$, 选取农田百分比、农村城市建设用地百分比、林地百分比、人口密度、单位土地 GDP 作为二级分区的 备选指标. 基于相关性分析, 识别出与水资源模数(河流的平均流量监测数据计算得出)、水质综合指标 (主 要污染物总磷、总氮、氨氮的综合值) 相关性大且空间异质性显著的指标, 作为水生态功能一、二级分区指 标. 构建的指标体系如表 1 所示.

表 1 一、二级分区指标体系

Tab. 1 Index system of level I and II ecological function regionalization

\begin{tabular}{cll}
\hline 指标级别 & 指标名称 & 指标描述 \\
\hline 一级 & 平均高程 & 通过降水和植被条件的差异影响水资源量 \\
& 湖库率 & 体现水文特征的对水域资源量的调节功能 \\
& 植被指数 $(N D V I)$ & 体现植被对水资源的涵养功能 \\
二级 & 农田土地利用百分比 & 反映水土流失、农田沟渠灌溉水下渗对水质污染的贡献 \\
& 农村城市建设用地百分比 & 反映农村、城市生活面源污染地表径流对水质污染的贡献 \\
& 人口密度 & 体现社会经济对水质的影响 \\
\hline
\end{tabular}

其中, 平均高程和湖库率的获取是基于分辨率为 $30 \mathrm{~m}$ 的 DEM 数据和流域水系矢量数据, 在 ArcGIS 9.3 软件环境下进行 Intersect 叠加、Zonal Statistics 分析、Summary Statistics 分析等一系列操作得到. 植被归一化 指数 $(N D V I)$ 利用 2007 年 $30 \mathrm{~m}$ 空间分辨率的 TM 影像, 在 ERDAS 9.2 中计算得出. 农田土地利用百分比和 农村城市建设用地百分比是利用 2007 年 $30 \mathrm{~m}$ 空间分辨率的 TM 影像, 进行遥感解译并结合实地调查生成 的滇池流域土地利用类型分布数据, 在 ArcGIS 中经过 Intersect 叠加、Summarize 统计得到. 人口密度的获取 是根据调查收集的滇池流域内的乡镇人口数据, 通过 ArcGIS 进行数据叠加和统计分析得到的.

\section{5 分区边界划定}

基于以上获取的空间分布数据,使用 ArcGIS 9.3 对分区指标进行空间叠加聚类,得到初步的分区结果. 再根据水资源模数的空间特征, 对一级分区边界进行微调. 根据水质综合指标空间特征, 对二级分区边界进 
行微调, 最终得到滇池流域水生态功能一、二级分区结果.

\section{2 分区结果与分析}

\section{1 基本单元划分结果}

滇池流域水生态功能一、二级分区子流域单元划分结果如图 1 所示. 滇池流域共划分了 22 个一级分区 子流域单元, 29 个二级分区子流域单元.
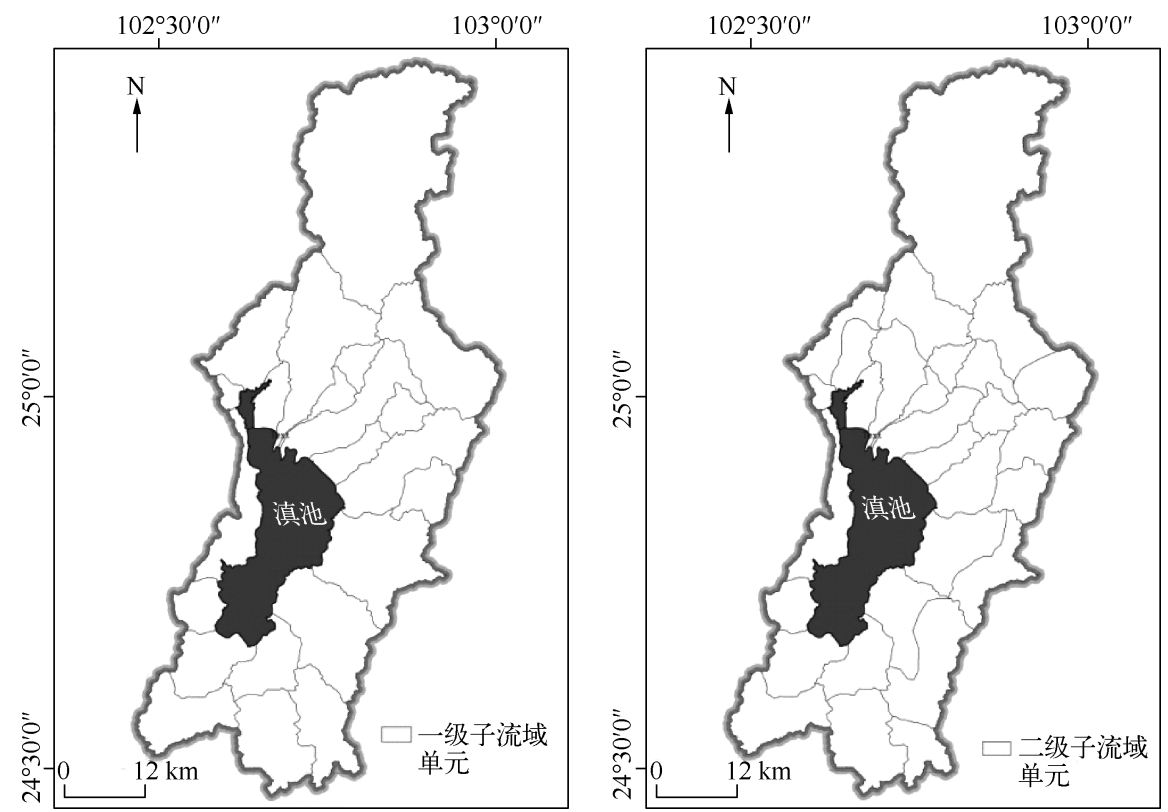

图 1 滇池流域一级分区和二级分区子流域单元

Fig. 1 Sub-catchment units of level I and level II ecological function regionalization in Lake Dianchi basin

\section{2 分区方案}

按照上述分区方法, 滇池流域分为 5 个一级区和 10 个二级区 (图 2). 水生态功能一级分区命名原则为: 流域方位或区域名称 + 水系类型 + 水生态功能一级区. 其中, 水系类型可分为山区河流和平原河流. 二级分 区命名的原则为: 流域方位或区域名称 + 水系名称或区段 + 生态系统类型 + 水生态功能亚区. 水系名称或 区段可分为上游水库、河流上游、河流中下游和湖体. 生态系统类型可分为森林、农田、城镇和湖体.

滇池流域 5 个水生态功能一级区和 10 个水生态功能二级区分别具有不同的生态系统区域特征, 各区在 高程、植被覆盖、湖库率土地利用方式和人口密度等方面均具有较大的差异性 (表 $2 、 3$ ). 全流域内各分区环 境驱动因子显著的空间变异性, 反映出流域景观结构和水生物群落的空间特征具有显著差异性和不均 匀性.

表 2 滇池流域水生态功能一级分区特征

Tab. 2 Characteristics of Level I water ecological function regionalization in Lake Dianchi basin

\begin{tabular}{clcccc}
\hline 分区编码 & 分区名称 & 单元面积 $/ \mathrm{km}^{2}$ & 高程 $/ \mathrm{m}$ & $N D V I$ & 湖库率/\% \\
\hline LGI & 北部水源地一山区河流一水生态功能一级区 & 773 & $2105 ~ 2840$ & 0.32 & 0.8 \\
LGII & 南部水源地一山区河流一水生态功能一级区 & 280 & 2099 & 0.37 & 1.1 \\
LGIII & 环滇池一平原河流一水生态功能一级区 & 1473 & 1900 & 0.20 & 0.5 \\
LGIV & 滇池一湖体一水生态功能一级区 & 298 & 1880 & -1.00 & 100 \\
LGV & 西山一海口河一水生态功能一级区 & 96 & 2012 & 0.30 & 0 \\
\hline
\end{tabular}



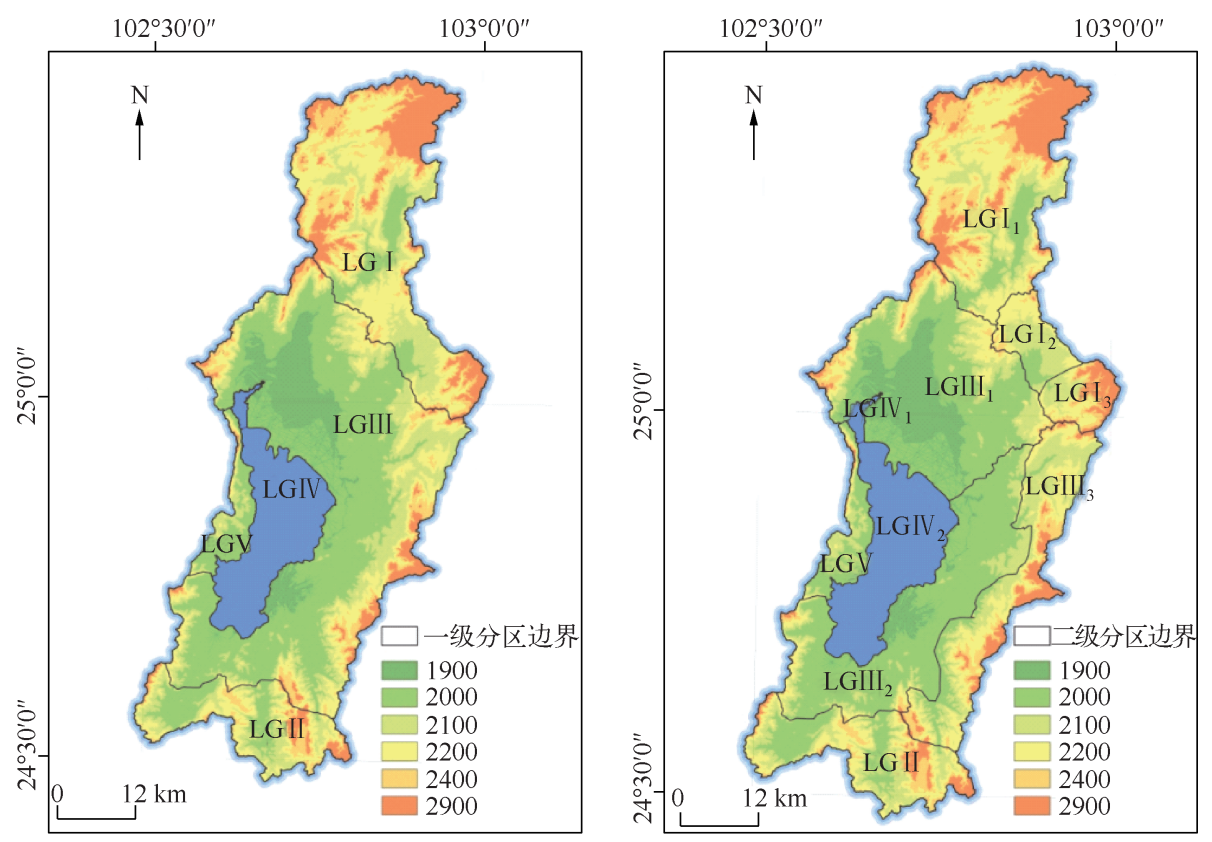

图 2 滇池流域水生态功能一级分区和二级分区

Fig. 2 Level I and level II water ecological function regionalization in Lake Dianchi basin

表 3 滇池流域水生态功能二级分区特征

Tab. 3 Characteristics of Level II water ecological function regionalization in Lake Dianchi basin

\begin{tabular}{clcccc}
\hline 分区编码 & 分区名称 & $\begin{array}{c}\text { 单元面积/ } \\
\mathrm{km}^{2}\end{array}$ & $\begin{array}{c}\text { 农田百分比/ 农村/城市建设用 } \\
\%\end{array}$ & $\begin{array}{c}\text { 人口密度/ } \\
(\text { 地百分比/\% }\end{array}$ \\
\hline $\mathrm{LGI}_{1}$ & 嵩明-松华坝水库-森林-水生态亚区 & 592 & 27.4 & 2.5 & 155 \\
$\mathrm{LGI}_{2}$ & 官渡-宝象河上游-农田-水生态亚区 & 96 & 32.1 & 11.9 & 198 \\
$\mathrm{LGI}_{3}$ & 官渡-宝象河水库-森林-水生态亚区 & 85 & 21.0 & 0.5 & 257 \\
$\mathrm{LGIII}_{1}$ & 昆明城区-人工河流-城镇-水生态亚区 & 631 & 20.6 & 38.2 & 3616 \\
$\mathrm{LGII}_{2}$ & 呈贡-中下游河流-农田-水生态亚区 & 504 & 56.9 & 13.4 & 445 \\
$\mathrm{LGII}_{3}$ & 呈贡-上游河流-森林-水生态亚区 & 338 & 31.4 & 3.4 & 221 \\
$\mathrm{LGIV}_{1}$ & 滇池北-草海-湖体-水生态亚区 & 11 & - & - & - \\
$\mathrm{LGIV}_{2}$ & 滇池南-外海-湖体-水生态亚区 & 287 & - & - & - \\
$\mathrm{LGII}$ & 晋宁-南部水库-森林-水生态亚区 & 280 & 26.5 & 3.9 & 169 \\
$\mathrm{LGV}$ & 西山-海口河-森林-水生态特区 & 96 & 27.5 & 10.1 & 604 \\
\hline
\end{tabular}

\section{3 合理性评价}

水生生物的选取是合理性评价的首要工作. 由于滇池流域外来鱼类引人较多, 形成养殖鱼类为主的单 一结构, 故选取分布广泛的着生藻类和底栖动物对分区结果进行合理性评价. 从一级分区结果来看, 北部 2 个上游子流域单元、南部 3 个上游子流域单元的指标综合值要明显高于中下游子流域单元. 通过着生藻类 的生物密度 DCA 分析 (图 3 ) 可以看出, 其物种的生物密度结构具有明显的规律性,同一分区内的着生藻类 的群落特征具有明显的同质性, 即在物种组成和优势种上都类似, LGIV 区滇池内的样点最为突出. 表明着 生藻类生物密度分布情况与一级分区结果吻合度较高, 证明了一级分区的合理性.

从二级分区结果来看, 环滇池平原的下游子流域单元指标综合值要明显高于流域外围的中上游子流域 单元指标综合值, 湖体北部的下游子流域单元指标综合值最大. 从底栖生物耐污种水丝蚓的生物密度 DCA 


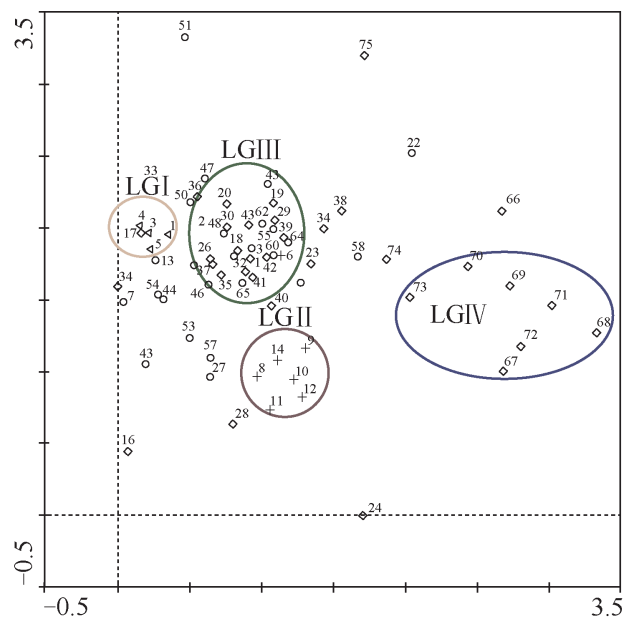

图 3 滇池流域着生藻类的生物密度 DCA 分析

Fig. 3 DCA analysis of periphytic algal density in Lake Dianchi basin

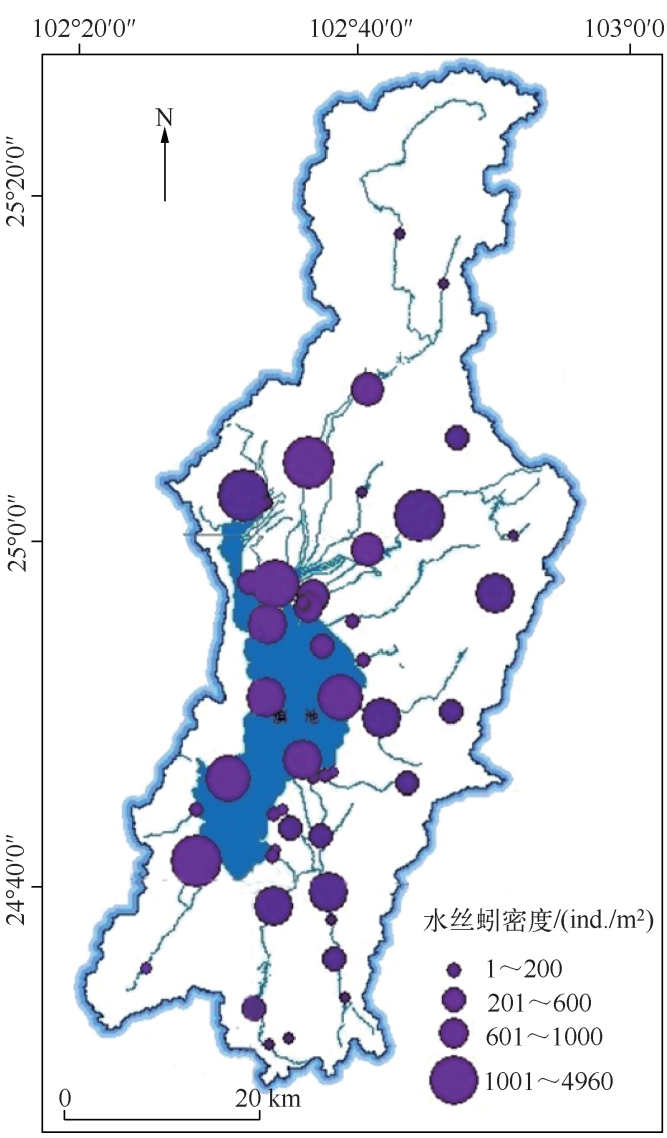

图 4 滇池流域水丝蚓的生物密度分布

Fig. 4 Distribution of Limnodrilus hoffmeisteri's density in Lake Dianchi basin
空间分布格局 (图 4 ) 可看出, 环湖体区域 $\left(\right.$ LGIII $_{1}$ 、 $\left.\mathrm{LGIII}_{2} 、 \mathrm{LGIII}_{3}\right)$ 水丝蚓生物密度都较大, 其中城区 $\left(\mathrm{LGIII}_{1}\right)$ 最大; 滇池 $\left(\mathrm{LGIV}_{1} 、 \mathrm{LGIV}_{2}\right)$ 次之, 而上游水 库区域 $\left(\mathrm{LGI}_{1} 、 \mathrm{LGI}_{2} 、 \mathrm{LGI}_{3} 、 \mathrm{LGII}\right)$ 的水丝蚓生物密度 较小, 其中 $\mathrm{LGI}_{2}$ 亚区较其它区域稍大, 这与滇池流 域的整体水质概况分布是一致的. 水丝蚓在水质较 好的二级分区密度较小, 在水质较差的二级分区中 密度较大,证明了二级分区的合理性.

\section{3 讨论和结论}

\section{1 讨论}

本文采用“自上而下”的演绎分区和 “自下而 上” 的归纳验证相结合的流域水生态功能分区思 路. 目前一些分区工作采用这种思路, 在海河、太湖 等大型流域的适用性较好, 具有一定的推广 性 ${ }^{[12-13,17-18,20,34]}$. 但并非对于所有流域、所有级别的 分区都适用 ${ }^{[35]}$. 分区思路的选择需充分考虑到研究 区域的尺度. 针对大尺度的高级别水生态功能分 区, 通常采用演绎方式进行划分; 针对小尺度流域 的水生态功能分区以及大尺度流域的低级别分区, 通常采用归纳方式进行划分 ${ }^{[36]}$. 目前我国并没有针 对各级水生态分区的具体内涵给出定义, 也没有明 确规定分区大小 ${ }^{[37]}$. 近年的研究多采用的是欧洲水 框架指令中的标准, 即面积在 $100 \sim 100000 \mathrm{~km}^{2}$ 的 流域可认为是大中尺度流域, 适合演绎法, 小于 $100 \mathrm{~km}^{2}$ 可以认为是小尺度流域, 适合归纳法. 本论 文的研究结果显示流域面积为 $2920 \mathrm{~km}^{2}$ 的滇池流 域为大中尺度流域, 采用演绎法分区效果较好. 但 是采用欧洲水框架指令中的标准仍然存在问题: 尺 度國值对于我国的流域是否合适? 因此, 结合我国 不同流域的特征, 开展生态功能区划与尺度效应的 研究, 对于指导不同流域的指标选择是十分必 要的.

指标选取的实质是判断各个指标对研究区域 异质性的表征能力和大小. 其作为整个生态功能区 划的基础, 通过对各个指标的重要性及其空间异质 性进行确定, 为指标综合归类提供依据. 本文在指 标的篮选过程中, 通过相关性分析识别了各个指标 对主导水生态功能的影响. 通过对比部分指标, 可 以发现湖泊流域与河流流域水系的主要因子的差 异. 通常河流流域或者平原大型湖泊流域的一级分 区指标中径流深作用明显 ${ }^{[12,14,16-17]}$, 与河流流域选 取的指标相比, 滇池流域篎选的一级分区的指标 中, 水文因子湖库率对其流域水资源支持功能的影 
响极为显著, 这主要是由于滇池人湖河流流量较小, 且空间差异性不显著, 导致湖泊水库对于整个流域的水 资源的影响占主导作用. 这充分体现了滇池流域特有的水系特征. 另外,气候因素对于水资源支持功能的影 响也不显著, 这可能是由于滇池流域相对河流流域 ${ }^{[12,14,16]}$ 面积较小, 气候因子的空间差异性不显著所导致 的. 在二级分区指标中, 滇池流域篎选的指标与河流流域有着较大差异. 考虑到滇池流域水质调节功能的降 低主要源于人类活动, 故从人类主导的土地利用方式以及社会经济两个方面进行选择. 针对各级指标体系, 采用等权重叠加法对分区指标进行综合. 实际上每个指标对该级分区主导功能的影响是有差异性的,采用 有权重差异性的定量化叠加方法, 可以更加客观地反映不同分区间主导功能的空间差异性 ${ }^{[38]}$.

选取何种水生生物以及采用何种生物指标是合理性评价的关键. 鱼类、底栖无脊椎动物、藻类、大型沉 水植物等是水生态系统的重要组成部分, 它们不仅分布广泛, 且能在不同尺度上对各类环境影响作出灵敏 响应、指示水生态系统特征 ${ }^{[28]}$. 鱼类由于其生长周期长、活动范围大等特点被广泛应用于国外的水生态分区 的验证. 但针对中国的多数流域来说, 比较适宜采用分布广泛、适应性较强的着生藻类和底栖动物. 本文合 理性评价结果显示, 滇池流域着生藻类和底栖动物对不同级别分区的响应不同, 底栖动物水丝蚓对于二级 分区的响应较高,这可能是水中有机污染空间差异显著造成的 ${ }^{[39]}$. 而着生藻对于一级分区的敏感性较高的 原因还未能给出合理的解释. 所以,针对不同流域、不同级别的分区, 需结合其主导生态功能、区域环境特征 等多方面因素选择水生生物. 另外, 本文采用了生物密度指标对分区结果进行评价, 而生物密度是水生生物 数量上密集程度的反映, 并没有反映出水生生物群落特征. 在未来的研究中, 基于多种水生生物, 结合种群 和个体的特征, 引人多样性指数等多种具有生态学意义的指标构建体系, 从而对分区结果进行定量化评价 是合理性评价的方向.

\section{2 结论}

1）滇池流域水生态功能一、二级分区的目的,分别体现了不同区域的水资源支持功能与水质调节功能 的空间差异. 根据滇池流域的尺度效应, 确定一级分区指标主要包括地形、水文、植被类型指标,二级分区主 要包括土地利用方式和人口指标.

2) 基于 GIS 的滇池流域水生态功能分区,采取的是 “子流域划分——驱动因子构建指标体系一一指标 综合聚类一一合理性评价”的分区技术路线,将滇池流域分成了 5 个一级区、10 个二级区 (图 3 ). 通过着生 藻和水蚓丝的生物密度分布特征,证明了分区的合理性.

3) 在滇池流域水生态功能分区工作中, 其指标的选取与河流流域以及平原湖泊流域均有一定的差异, 对其他高原湖泊流域的水生态功能区划具有一定的指导意义. 但在指标综合聚类和合理性评价工作中仍然 存在不足,需要在以后的工作中改进完善.

\section{4 参考文献}

[ 1 ] 黄 艺,蔡佳亮, 吕明姬等. 流域水生态功能区划及其关键问题. 生态环境学报, 2009,18(5) : 1995-2000.

[ 2 ] Abell R, Thieme ML, Revenga C et al. Freshwater ecoregions of the world: a new map of biogeographic units for freshwater biodiversity conservation. BioScience, 2008, 58(5): 403-414.

[ 3 ] Hemsley-Flint B, Wright JF, Sutcliffe DW et al. Classification of the biological quality of rivers in England and Wales. In: Wright JF, Sutcliffe DW, Furse MT et al. Assessing the biological quality of fresh waters RIVPACS and other techniques. Cumbria: Freshwater Biological Association, 2000.

[ 4 ] Wright JF, Sutcliffe DW, Furse MT. Assessing the biological quality of fresh waters rivpacs and other techniques. Cumbria: Freshwater Biological Association,2000: 113-124.

[ 5 ] Moog O, Schmidt-Kloiber A, Ofenböck T et al. Does the ecoregion approach support the typological demands of the EU 'Water Framework Directive'? In: Hering D, Veidonschot PFM, Moog O et al eds. Integrated Assessment of Running Waters in Europe. Dordrecht: Springer Netherlands, 2004: 21-33.

[ 6 ] 孟 伟,张 远,郑丙辉. 水生态区划方法及其在中国的应用前景. 水科学进展, 2007, 18 (2):293-300.

[ 7 ] 孙小银, 周启星,于宏兵等. 中美生态分区及其分级体系比较研究. 生态学报, 2010,30 (11) : 3010-3017.

[8 ] 孙小银,周启星. 中国水生态分区初探. 环境科学学报,2010,30(2):415-423.

[ 9 ] 马溪平, 周世嘉, 张 远等. 流域水生态功能分区方法与指标体系探讨. 环境科学与管理, 2010,35(12):59-64. 
[10] 孟 伟, 张 远, 张 楠等. 流域水生态功能分区与质量目标管理技术研究的若干问题. 环境科学学报, 2011,31 (7) : $1345-1351$.

[11] 孟 伟, 张 远, 张 楠等. 流域水生态功能区概念、特点与实施策略. 环境科学研究,2013,26(5):465-471.

[12] 孙然好,汲玉河,尚林源等. 海河流域水生态功能一级二级分区. 环境科学,2013,34(2):509-516.

[13] 李法云, 范志平, 张 博等. 辽河流域水生态功能一级分区指标体系与技术方法. 气象与环境学报, 2012, 28 (5): $83-89$.

[14] 孟 伟,张 远,郑丙辉. 辽河流域水生态分区研究. 环境科学学报,2007,27(6):911-918.

[15] 张 博. 辽河流域水生态功能一、二级分区研究 [学位论文].沈阳:辽宁大学,2011.

[16] 张 楠,张 远,孔维静等. 太子河流域水生态功能 II 级区的划分. 环境科学研究,2013,26 (5):472-479.

[17］高永年,高俊峰.太湖流域水生态功能分区. 地理研究,2010,29(1):111-117.

[18］高永年,高俊峰,陈垌烽等.太湖流域水生态功能三级分区. 地理研究,2012,31(11):1941-1951.

[19] 王传辉, 吴 立, 王心源等. 基于遥感和 GIS 的巢湖流域生态功能分区研究. 生态学报,2013,33(18):5808-5817.

[20］杨顺益,唐 涛,蔡庆华等. 洱海流域水生态分区.生态学杂志,2012,31(7):1798-1806.

[21] 于 洋,张 民, 钱善勤等. 云贵高原湖泊水质现状及演变. 湖泊科学, 2010,22(6):820-828.

[22］陈利顶,傅伯杰,赵文武. “源” “汇” 景观理论及其生态学意义. 生态学报,2006,26(5) : 1444-1449.

[23] 邓红兵,王庆礼,蔡庆华. 流域生态学——新学科、新思想、新途径. 应用生态学报, 1998,9(4):108-114.

[24] 李婉晖,潘文斌, 邓红兵. 水资源利用与保护的途径一一流域管理. 生态学杂志, 2004,23(6):97-101.

[25] 吴 刚,蔡庆华. 流域生态学研究内容的整体表述. 生态学报,1998,18(6):13-19.

[26] 蔡佳亮,殷 贺,黄 艺. 生态功能区划理论研究进展. 生态学报,2010,30(11):3018-3027.

[27] 郭慧光. 滇池治理与滇中调水. 环境科学导刊,2007,26(6):30-33.

[28] 唐 涛,蔡庆华. 水生态功能分区研究中的基本问题. 生态学报,2010,30(22):6255-6263.

[29] Omernik JM. Ecoregions of the conterminous United States. Annals of the Association of American Geographers, 1987,77 (1) : $118-125$.

[30］黄 艺, 蔡佳亮, 郑维爽等. 流域水生态功能分区以及区划方法的研究进展. 生态学杂志, 2009,28(3):542-548.

[31］李艳梅,曾文炉,周启星. 水生态功能分区的研究进展. 应用生态学报,2009,20(12):3101-3108.

[32］刘星才,徐宗学,徐 琛. 水生态一、二级分区技术框架. 生态学报,2010,30(17):4804-4814.

[33] 张 洪, 陈 震, 张 帅等. 云南省高原湖泊流域土地利用与水环境变化异质性研究. 水土保持通报, 2012,32(2): 255-260.

[34] 刘素平. 辽河流域三级水生态功能分区研究 [学位论文]. 沈阳:辽宁大学,2011.

[35] Newall P, Wells F. Potential for delineating indicator-defined regions for streams in Victoria, Australia. Journal of the North American Benthological Society, 2000, 19(3) : 557-571.

[36] 黄晓霞,江 源,熊 兴等.水生态功能分区研究. 水资源保护,2012,28(3):22-27.

[37] 刘星才, 徐宗学, 张淑荣等. 流域环境要素空间尺度特征及其与水生态分区尺度的关系一一以辽河流域为例. 生态 学报,2012,32(11):3613-3620.

[38] 于世伟, 陈 贺, 曾 容等. 定量化方法在生态分区过程中的应用及案例研究. 水土保持研究, 2010,17(4): 247-251.

[39] 文 航, 蔡佳亮, 苏 玉等. 利用水生生物指标识别滇池流域人湖河流水质污染因子及其空间分布特征. 环境科学 学报,2011,31(1):69-80. 